\title{
Cervical Myelopathy Caused by Intracranial Dural Arteriovenous Fistula
}

\author{
Won Young Kim, Jin Bum Kim, Taek Kyun Nam, Young Baeg Kim, Seung Won Park \\ Department of Neurosurgery, Chung-Ang University College of Medicine, Seoul, Korea
}

Intracranial dural arteriovenous fistula (dAVF) usually results in various problems in the brain. But it can be presented as a myelopathy, which may make early diagnosis and management to be difficult. We recently experienced a case of cervical myelopathy caused by intracranial dAVF. A 60-year-old man presented with a 3-year history of gait disturbance due to a progressive weakness of both legs. Neurological examination revealed spastic paraparesis (grade IV) and Babinski sign on both sides. Magnetic resonance imaging showed serpentine vascular signal voids at C2-T1 on T2-weighted image with increased signal intensity and swelling of spinal cord at $\mathrm{C} 1-\mathrm{C} 4$. We performed a brain computed tomography angiography and found intracranial dAVF with multiple arteriovenous shunts. Venous drainages were noted at tentorial veins and cervical perimedullary veins. After Onyx embolization, the patient showed gradual improvement in motor power and gait disturbance. The venous drainage pattern is a well-known prognostic factor of dAVF. In our case, the intracranial dAVF drained to spinal perimedullary vein, which seemed to result in the ischemic myelopathy. Although it is rare condition, it sometimes can cause serious complications. Therefore, we should keep in mind the possibility of intracranial dAVF when a patient presents myelopathy.

Key Words: Brain · Arteriovenous fistula $\cdot$ Ischemia $\cdot$ Spinal cord diseases

\section{INTRODUCTION}

Intracranial dural arteriovenous fistula (dAVF) usually results in various problems of the brain like seizure or hemorrhage $^{2,8)}$. But it sometimes can be presented with symptoms of myelopathy, which may make diagnosis and early management to be quite difficult. We recently experienced a case of upper cervical myelopathy caused by intracranial dAVF without any spinal vascular malformation.

\section{CASE REPORT}

A 60-year-old man visited Chung-Ang University Hospital with a 3-year history of progressive gait disturbance. Neurological examination revealed motor weakness (grade IV) of both legs with spastic gait and bilateral pathologic reflexes, Babinski sign and ankle clonus. Pain, temperature, and proprioceptive sensations were normal. Sphincter functions were well preserved. Cervical magnetic resonance imaging (MRI) showed serpentine vascular signal void from $\mathrm{C} 1$ to $\mathrm{T} 1$, and diffuse cord edema and swelling at $\mathrm{C} 1$ to $\mathrm{C} 4$ (Fig. 1). The first diag-

- Received: May 9, 2016 • Revised: May 29, 2016

- Accepted: May 30, 2016

Corresponding Author: Seung Won Park

Department of Neurosurgery, Chung-Ang University Hospital, 102

Heukseok-ro, Dongjak-gu, Seoul 06973, Korea

Tel: +82-2-6299-3190, Fax: +82-2-6299-2069

E-mail: nspsw@cau.ac.kr

$\otimes$ This is an open access article distributed under the terms of the Creative Commons Attribution Non-Commercial License (http://creativecommons.org/licenses/by-nc/4.0/) which permits unrestricted non-commercial use, distribution, and reproduction in any medium, provided the original work is properly cited. nostic impression was spinal arteriovenous fistula. We performed spinal angiography, but there was no evidence of vascular abnormality at the cervicothoracic spine. Then, we performed brain computed tomography angiography (CTA) to screen possible intracranial vascular abnormalities (Fig. 2). The brain CTA revealed dAVF at the posterior fossa, and subsequent transfemoral cerebral arteriography confirmed the vascular abnormalities (Figs. 2, 3). The dAVF received multiple arterial supplies from the meningohypophyseal artery of internal caro-
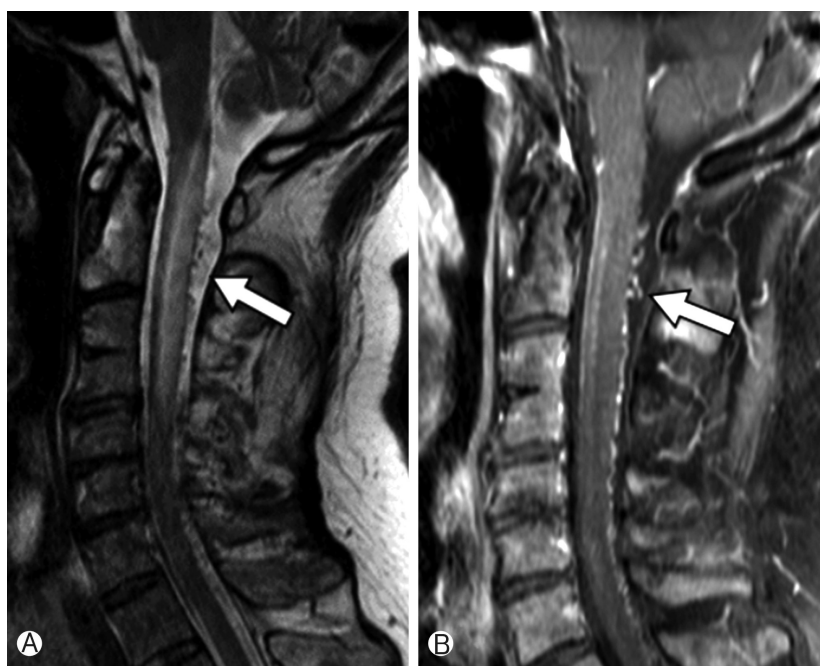

Fig. 1. (A) Cervical T2-weighted magnetic resonance imaging (MRI) showed serpentine vascular signal void (white arrow) at the $\mathrm{C} 1-\mathrm{T} 1$ region and diffuse edema in the spinal cord at $\mathrm{C} 1-$ C4. (B) Abnormal perimedullary vascular enhancement (white arrow) noted on contrast enhanced MRI. 


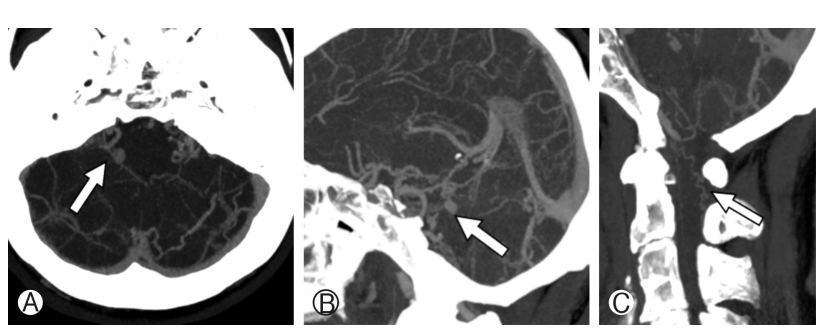

Fig. 2. (A, B) Brain computed tomography angiography (CTA) showed abnormally dilated venous channels (white arrow) in the posterior fossa suggesting dural arteriovenous fistula. (C) Cervical perimedullary veins noted on Brain CTA (white arrow).
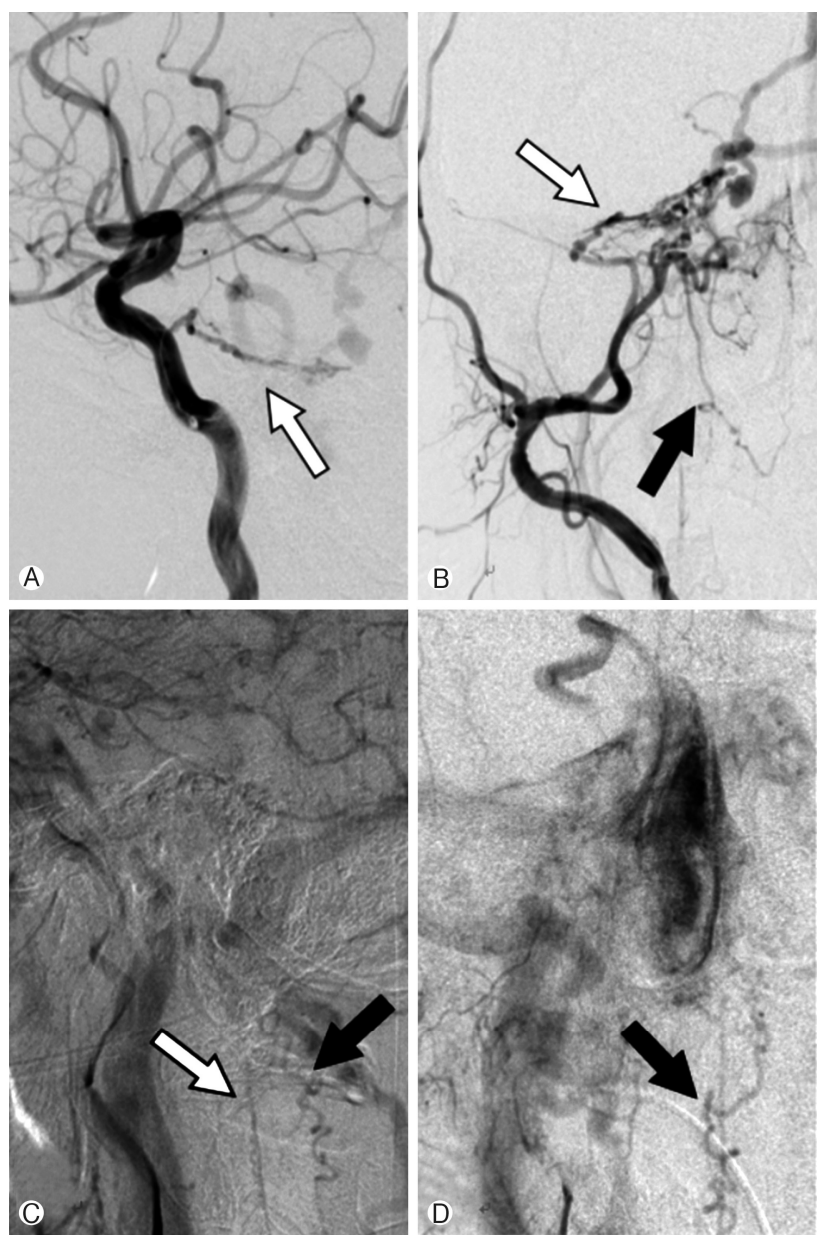

Fig. 3. (A) Arterial phase of right internal carotid angiogram showing arteriovenous fistula from the artery of the meningohypophyseal trunk (white arrow). (B) Arterial phase of right external carotid angiogram showing fistulas from the artery of foramen rotundum (black arrow) and the petrosal branch of the right middle meningeal artery (white arrow). (C) Venous phase of right internal carotid angiogram shows venous drainages to the prepontine (white arrow) and cervical perimedullary veins (black arrow). (D) Venous phase of right external carotid angiogram shows venous drainages to the cervical perimedullary vein (black arrow).
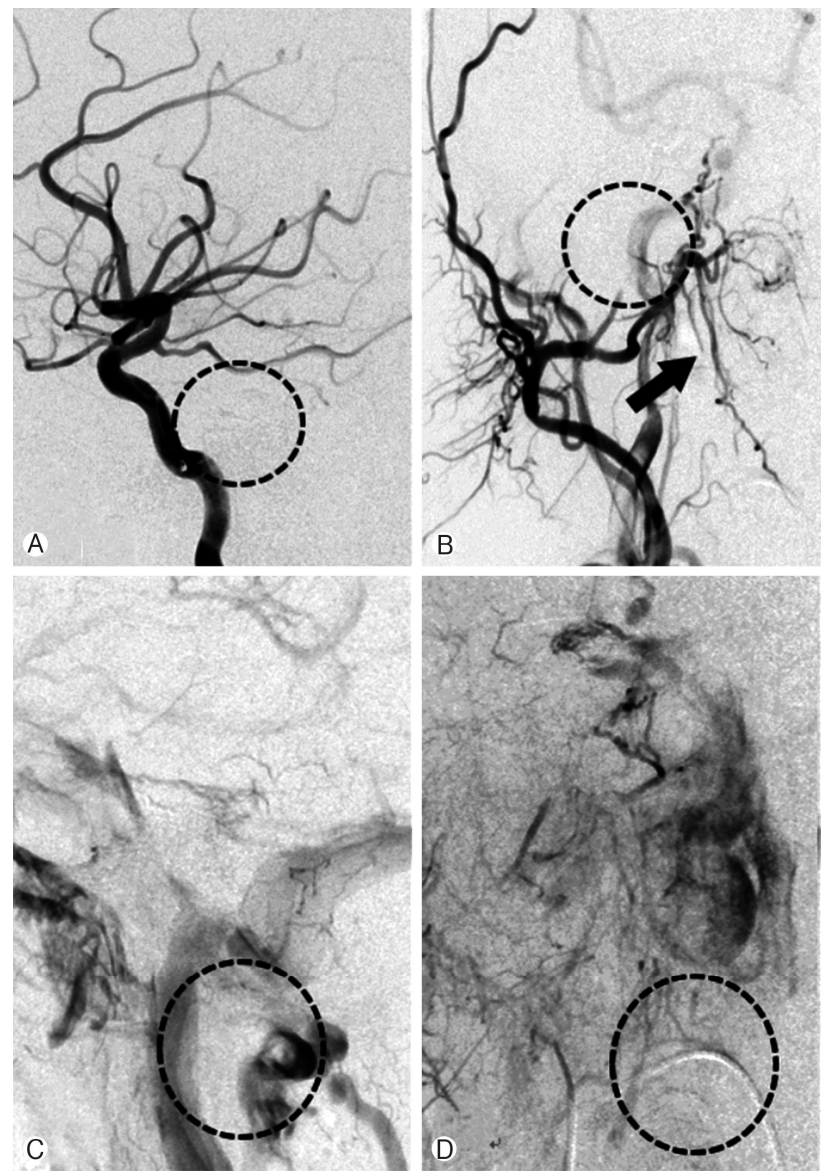

Fig. 4. Postembolization angiographs. (A) Arterial phase of right internal carotid angiogram shows complete occlusion of fistulas from the artery of the meningohypophyseal trunk (dashed circle). (B) Arterial phase of right external carotid angiogram shows complete occlusion of fistulas from the petrosal branch of the right middle meningeal artery (dashed circle) and residual fistula from the artery of the foramen rotundum (black Arrow). (C) Venous phase of right internal carotid angiogram shows complete occlusion of the prepontine and cervical perimedullary veins (dashed circle). (D) Venous phase of right external carotid angiogram shows complete occlusion of drainages to the cervical perimedullary vein (dashed circle).

tid artery, artery of foramen rotundum, and petrosal branch of right middle meningeal artery. Venous drainages were connected to prepontine vein and cervical perimedullary vein (Fig. 3).

We performed Onyx embolization under general anesthesia. We could not occlude all the feeding arteries, remaining 2 residual fistulas from the foramen rotundum artery. However, basal and spinal perimedullary drainages were completely disappeared (Fig. 4). One day after the embolization, motor power of both legs improved to grade $\mathrm{V}$ with decreased spasticity bilaterally. The patient received physiotherapy at the department of rehabilitation medicine, and discharged at 4 weeks after the embolization with full motor power but mild spas- 
ticity. One year after the embolization, we performed brain CTA, there were decreased diameter of transverse pontine vein, aneurysmal dilatation in right mesencephalic vein and no other abnormal density in the brain. He still showed full motor power and mild spasticity.

\section{DISCUSSION}

Intracranial dAVF consists of pathological shunts connecting dural arteries with dural or cortical veins ${ }^{4)}$. Intracranial dAVF accounts for $10 \%-15 \%$ of intracranial arteriovenous malformations $(\mathrm{AVMs})^{4)}$. Intracranial dAVF may induce myelopathy by interruption of cervical spinal venous drainage ${ }^{4)}$. Cases of dAVF have been reported rarely since the first report in $1982^{9}$. Our case also showed cervical myelopathy caused by an intracranial dAVF draining to the cervical perimedullary vein.

Symptoms of intracranial dAVF are known to largely depend on the patterns of venous drainage ${ }^{4)}$. There are 2 types of dAVF classification, Borden or Cognard classification systems, according to the patterns of venous drainage ${ }^{4)}$. The Borden classification divides the lesions according to the site of venous drainage and the presence of cortical venous drain$\mathrm{age}^{1)}$. The venous drainages were the dural sinus without cortical venous drainage in type I, the dural sinus with cortical venous drainage in type II, and the direct cortical venous drainage in type III. The Cognard classification divides the lesions by the direction of dural sinus flow, cortical venous drainage, and shape of draining cortical vein ${ }^{2}$. Type I shows drains to the dural sinus with antegrade flow without cortical venous drainage. Type II has drains to the dural sinus like type I, which can be reclassified into 3 subtypes, Type IIa, retrograde flow without cortical venous drainage, type IIb, antegrade flow with cortical venous drainage, and type IIa $+b$, retrograde flow with cortical venous drainage. Type III shows direct drains to cortical veins. type IV is type III with drains to ectatic cortical veins. Type $\mathrm{V}$ has direct drains to spinal perimedullary veins. The type of venous drainage seems to relate closely with the clinical course of dAVF. Previous papers reported cases of myelopathy in the patients with Borden type III and Cognard type $\mathrm{V}^{1,2}$. According to the type of our patient's dAVF, Borden type III and Corgnard type V, he seemed to have high risk of complications such as neurological deficit, bleeding, and myelopathy.

Diagnosis of the dAVF can be confirmed by clinical impression and high-resolution imaging including computed tomography and MRI, and its type can be classified with cerebral angiography ${ }^{4)}$. Congestion and swelling of the blood vessels of the spinal cord are useful markers for the initial diagnosis, ${ }^{4,7}$. In our case, serpentine vascular signal void and diffuse edema of cervical spinal cord appeared on T2-weighted MRI. The serpentine vessels could be identified more clearly on contrast enhanced MRI. These findings are known to be clues for initial impression of both spinal dAVF and intracranial dAVF. To distinguish them, both cerebral and spinal angiographies are required. However, if a patient shows myelopathy, the spinal vascular abnormality may be considered as a causative pathology more likely than the intracranial vascular lesion. Discrepancy between the anatomical sites of clinical symptoms and lesions can delay the diagnosis and proper treatment. Considering its serious complications, we should keep in mind a possibility of intracranial vascular abnormality as a cause of cervical myelopathy ${ }^{10)}$. We initially performed spinal angiography because myelopathy was the initial problem. After the negative finding of the spinal angiography, we decided immediately to perform brain CTA as a screening test for brain lesion, and we could make an early diagnosis of intracranial dAVF with spinal cord lesion. Early diagnosis and early management are important for the favorable prognosis of dAVF especially in the case of high-risk types, Borden type III and Cognard type $\mathrm{V}^{4,7}$.

Endovascular treatment is known to be the treatment of choice, and surgical treatment is a second option in cases the endovascular treatment is not feasible ${ }^{4}$. The treatment goal is to solve the venous hypertension by complete occlusion of all arteriovenous shunts). If the fistulas and draining veins are not completely blocked, collateral vessels can be recruited and the bleeding risk will persist. However, when the complete occlusion is too difficult, selective occlusion of accessible fistulas may be the safer choice ${ }^{7}$. We conducted an endovascular embolization with Onyx, a nonadhesive embolic agent composed of ethyl alcohol-dimethyl sulfoxide ${ }^{9)}$. It has been used for embolization of AVMs since the late 1980s and has been increasingly used in the recent years because of its ease of use ${ }^{3,6,9,11}$. The advantage of Onyx is that the operator can control its volume and rate of delivery ${ }^{5)}$. However, it requires longer time (7-100 minutes) to see the obliteration of the AVMs with fluoroscopic examination comparing to N-butylcyanoacrylate (less than 1 minute), which may increase the radiation exposure ${ }^{5)}$. In our case, we chose Onyx embolization because of the multiple feeding arteries to the lesion. Some feeders were too small or had too complicated curvature for selection, which made the endovascular occlusion to be incomplete. There were residual fistulas from artery of foramen rotundum after the embolization finished, but, fortunately, the perimedullary venous drainage was disappeared completely (Fig. 4).

\section{CONCLUSION}

The venous drainage pattern of intracranial dAVF seems to relate closely with the risk of complications. When the intracranial dAVF drains to the spinal perimedullary vein, it can inhibit the circulation of spinal cord and result in the ischemic myelopathy. Even though it is rare condition, we should keep in mind the possibility of intracranial dAVF when a patient shows cervical myelopathy without any spinal vascular abnormality. 


\section{CONFLCT OF INTEREST}

No potential conflict of interest relevant to this article was reported.

\section{ACKNOWLEDGMENTS}

This work was supported by the Technology Innovation Program (ATC; Advanced Technology Center, 10048523, Development of fluorography system under $50 \%$ irradiation dose with image quality on par with angiographic equipment to global leader in next generation) funded by the Ministry of Trade, Industry and Energy (MI, Korea).

\section{REFERENCES}

1. Borden JA, Wu JK, Shucart WA: A proposed classification for spinal and cranial dural arteriovenous fistulous malformations and implications for treatment. J Neurosurg 82:166-179, 1995

2. Cognard C, Gobin YP, Pierot L, Bailly AL, Houdart E, Casasco A, et al: Cerebral dural arteriovenous fistulas: clinical and angiographic correlation with a revised classification of venous drainage. Radiology 194:671-680, 1995

3. Cognard C, Januel AC, Silva NA Jr, Tall P: Endovascular treatment of intracranial dural arteriovenous fistulas with cortical venous drainage: new management using Onyx. AJNR Am J Neuroradiol 29:235-241, 2008
4. Gandhi D, Chen J, Pearl M, Huang J, Gemmete JJ, Kathuria S: Intracranial dural arteriovenous fistulas: classification, imaging findings, and treatment. AJNR Am J Neuroradiol 33:10071013, 2012

5. Guedin P, Gaillard S, Boulin A, Condette-Auliac S, Bourdain F, Guieu S, et al: Therapeutic management of intracranial dural arteriovenous shunts with leptomeningeal venous drainage: report of 53 consecutive patients with emphasis on transarterial embolization with acrylic glue. J Neurosurg 112:603-610, 2010

6. Katsaridis V, Papagiannaki C, Aimar E: Curative embolization of cerebral arteriovenous malformations (AVMs) with Onyx in 101 patients. Neuroradiology 50:589-597, 2008

7. Kim NH, Cho KT, Seo HS: Myelopathy due to intracranial dural arteriovenous fistula: a potential diagnostic pitfall. Case report. J Neurosurg 114:830-833, 2011

8. Lasjaunias P, Chiu M, ter Brugge K, Tolia A, Hurth M, Bernstein M: Neurological manifestations of intracranial dural arteriovenous malformations. J Neurosurg 64:724-730, 1986

9. Nogueira RG, Dabus G, Rabinov JD, Eskey CJ, Ogilvy CS, Hirsch JA, et al: Preliminary experience with onyx embolization for the treatment of intracranial dural arteriovenous fistulas. AJNR Am J Neuroradiol 29:91-97, 2008

10. Ricolfi F, Manelfe C, Meder JF, Arrué P, Decq P, Brugiéres $\mathrm{P}$, et al: Intracranial dural arteriovenous fistulae with perimedullary venous drainage. Anatomical, clinical and therapeutic considerations. Neuroradiology 41:803-812, 1999

11. Tomak PR, Cloft HJ, Kaga A, Cawley CM, Dion J, Barrow DL: Evolution of the management of tentorial dural arteriovenous malformations. Neurosurgery 52:750-760, 2003 